\title{
Vascular Diseases of the Spleen: A Review
}

\author{
Pearl Princess D. Uy*1,4 , Denise Marie Francisco ${ }^{1}$, Anshu Trivedi ${ }^{2}$, Michael O'Loughlin ${ }^{3}$ \\ and George Y. Wu ${ }^{1}$ \\ ${ }^{1}$ Department of Medicine, University of Connecticut Health Center, Farmington, CT, USA; ${ }^{2}$ Department of Pathology, Hartford \\ Hospital, Hartford, CT, USA; ${ }^{3}$ Department of Radiology, Hartford Hospital, Hartford, CT, USA; ${ }^{4}$ Department of Gastroenterology \& \\ Hepatology, University of Connecticut Health Center, Farmington, CT, USA
}

\begin{abstract}
Vascular diseases of the spleen are relatively uncommon in the clinical practice. However, the reported incidence has been progressively increasing, probably due to advances in the imaging modalities used to detect them. This disease condition often presents with non-specific clinical manifestations, but can be associated with significant morbidity and mortality. This review article aims to provide updated clinical information on the different vascular diseases of the splenic vasculature-splenic vein thrombosis, splenic vein aneurysm, splenic artery aneurysm, splenic arteriovenous fistula, and spontaneous splenorenal shunt-in order to aid clinicians in early diagnosis and management.
\end{abstract}

Citation of this article: Uy PPD, Francisco DM, Trivedi A, O'Loughlin M, Wu GY. Vascular diseases of the spleen: a review. J Clin Transl Hepatol 2017;5(2):152-164. doi: 10.14218/ JCTH.2016.00062.

\section{Introduction}

The spleen has an important role in the immune function and hematopoiesis of the body. A diseased or surgically absent spleen increases the risk for infections with encapsulated bacteria. In addition, it may be secondarily involved in certain oncologic, infectious, hepatic and pancreatic diseases or secondary to trauma or iatrogenic causes. Diseases of the spleen, especially those involving the splenic vessels, are rare, and the diagnoses are often missed due to lack of or nonspecific clinical symptoms. Delayed diagnosis and treatment of splenic diseases, however, can lead to catastrophic complications that include splenic rupture and death. Moreover, emergent surgical interventions are also associated with higher peri- and postoperative morbidity and mortality rates. The recent advances in imaging modalities have allowed for vascular diseases of the spleen to be increasingly diagnosed

Keywords: Splenic vein thrombosis; Splenic vein aneurysm; Splenic artery aneurysm; Splenic arteriovenous fistula; Spontaneous splenorenal shunt.

Abbreviations: $\mathrm{CT}$, computed tomography; DSA, digital subtraction angiography; EGD, esophagogastroduodenoscopy; EUS, endoscopic ultrasound; GI, gastrointestinal; HCC, hepatocellular carcinoma; MDCTA, multidetector computed tomographic angiography; MRA, magnetic resonance angiography; MRI, magnetic resonance imaging; PSVT, portal or splenic vein thrombosis; SAA, splenic artery aneurysm; SAVF, splenic arteriovenous fistula; SSRS, spontaneous splenorena shunt; SVA, splenic vein aneurysm; SVT, splenic vein thrombosis; US, ultrasound. Received: 13 November 2016; Revised: 15 February 2017; Accepted: 23 February 2017

*Correspondence to: Pearl Princess D. Uy, Department of Medicine, University of Connecticut Health Center, 263 Farmington Avenue, Farmington, CT 06030-1235, USA. Tel: +1-860-810-9608, Fax: +1-860-679-4613, E-mail: uy@uchc.edu at early stages and in asymptomatic phases, allowing for elective surgeries, less invasive endovascular surgeries or observation with serial imaging to be performed. Early recognition by clinical examination and diagnostic imaging is important for timely intervention, improved clinical outcomes, and increased survival rates.

\section{Splenic vasculature}

The main arterial supply of the spleen is the splenic artery. It courses to the left, along the superior border of the pancreas, posterior to the omental bursa, and anterior to the left kidney. It divides into 5 or more branches that enter the hilum of the spleen, within the splenorenal ligament. As the splenic artery passes the superior border of the pancreas, it gives off small arterial branches that supply the pancreatic neck, tail, and body. ${ }^{1,2}$ It also provides the short gastric arteries that supply the fundus of the stomach, and left gastro-omental artery which courses along the greater curvature of the stomach. ${ }^{1,2}$ The splenic vessels do not anastomose, resulting in 2 or 3 distinct vascular segments. Between these segments are avascular planes that can be used to minimize blood loss during subtotal splenectomies. ${ }^{1,2}$

The main vascular drainage of the spleen occurs through the splenic vein. Tributaries include the short gastric veins from the fundus and greater curvature of the stomach, the left gastroomental vein from the greater curvature of the stomach, pancreatic veins that drain the pancreatic body and tail, and the inferior mesenteric vein. ${ }^{1,2}$ It courses to the right and lies inferior to the splenic artery, passing through the splenorenal ligament. The inferior mesenteric vein unites with the splenic vein, as it courses posterior to the pancreatic body and tail. Then, the splenic vein joins the superior mesenteric vein to form the hepatic portal vein, posterior to the neck of the pancreas. $^{1,2}$ Several anatomical variations in the branching of the splenic vessels within the hilum have been described, which can be important during splenic surgery. And lastly, a thin fibrous capsule surrounds the spleen. From the capsule, connective tissue trabeculae extend into the splenic parenchyma to the hilum, including the branches of the splenic artery and vein. ${ }^{3}$

Diseases of the splenic vasculature

\section{Splenic vein thrombosis}

Splenic vein thrombosis (SVT) is often related to a pancreatic pathology, because of the close anatomical relationship between the splenic vein and the pancreas. SVT may also occur due to intrinsic endothelial damage to the splenic vein 
from thrombosis or neoplasm, from propagation of a portal vein clot and erosion of a pseudocyst into the splenic vein, or it may result from external splenic vein compression by a pseudocyst, fibrosis or lymphadenopathy that leads to venous stasis and thrombosis. ${ }^{4}$ There should be a high index of suspicion for SVT in a patient with pancreatitis who presents with new-onset gastrointestinal (GI) bleeding, in a patient with isolated gastric varices, or in a patient with splenomegaly in the absence of cirrhosis, portal hypertension or hematologic diseases. ${ }^{4}$ In a large case series by Agarwal et al., ${ }^{5}$ out of the 157 patients who were treated for chronic pancreatitis, the incidence of SVT was $22 \%$. This result was further supported by a meta-analysis performed by Butler et al. ${ }^{6}$ that showed a $22.6 \%$ incidence of pancreatitis-induced SVT among those with acute pancreatitis, and $12.4 \%$ for those with chronic pancreatitis. A prior literature review by Sutton et al. ${ }^{7}$ involving 53 cases of isolated SVT reported that $52 \%$ of patients had a pancreatic disease. Other identified causes of SVT in the literature are summarized in Table $1 . .^{4-17}$

Although the clinically described triad of SVT includes splenomegaly, normal liver enzymes and upper GI bleeding, SVT is diagnosed most often on imaging. ${ }^{4-7,11}$ Increased pressure within the splenic vein from the thrombosis can lead to a localized form of portal hypertension called "sinistral" or "left-sided" portal hypertension, where the venous drainage of the spleen occurs by the collateral circulation that includes the short and posterior gastric veins to the coronary veins, and the gastroepiploic veins to the superior mesenteric vein. ${ }^{6,7}$ The formation of gastric varices is related to the dilation of the submucosal venous reticulum of the gastric fundus which connects the coronary veins, short and posterior gastric veins. ${ }^{13,18}$ The mechanism by which splenomegaly develops is not clear, but may be related to increased splenic venous congestion and splenic arterial blood flow, that may cause hemorrhage, infarction, and-in rare cases-rupture. ${ }^{19}$ It has been clearly shown that splenomegaly is not due to portal hypertension per se. ${ }^{19}$

Historically, patients would often present with chronic abdominal pain and upper GI bleeding. However, with the availability of imaging studies, SVT is now often diagnosed in asymptomatic patients. ${ }^{6,20}$ In a prospective study by Koklu et al., ${ }^{19} 37.5 \%$ presented with abdominal pain, whereas $29.2 \%$ had GI bleeding. This reported incidence of GI bleeding was further confirmed in the meta-analysis by Butler et al., ${ }^{6}$ which only included studies published after 1995, where $53 \%$ of patients had varices and $12.3 \%$ had GI bleeding. This is in contrast to the findings of Sutton et al., 7 which showed a $64 \%$ incidence of GI hemorrhage among the 53 cases of isolated SVT on prior literature review. This may be explained by the earlier diagnosis and treatment of SVT with the advent of more advanced imaging tools. In the same meta-analysis, splenomegaly was only noted in $42-54 \%$ of patients with pancreatitis-induced SVT, which supports the notion that not all patients with SVT present with splenomegaly. ${ }^{6}$

\section{Diagnostics}

Because it is non-invasive and inexpensive, abdominal ultrasound (US) is often the first imaging test used to search for SVT. Its accuracy is comparable to angiography and arterial

Table 1. Summary on the etiologies of the different vascular diseases of the spleen

\begin{tabular}{|c|c|c|c|c|}
\hline $\begin{array}{l}\text { Splenic Vein Thrombosis } \\
\text { (SVT) }\end{array}$ & $\begin{array}{l}\text { Splenic Vein } \\
\text { Aneurysm (SVA) }\end{array}$ & $\begin{array}{l}\text { Splenic Artery } \\
\text { Aneurysm (SAA) }\end{array}$ & $\begin{array}{l}\text { Splenic Arteriovenous } \\
\text { Fistula (SAVF) }\end{array}$ & $\begin{array}{l}\text { Spontaneous } \\
\text { Splenorenal } \\
\text { Shunt (SSRS) }\end{array}$ \\
\hline $\begin{array}{l}\text { - Pancreatic disease (acute } \\
\text { pancreatitis, } \\
\text { chronic pancreatitis, } \\
\text { pseudocyst, abscess, } \\
\text { malignancy) } \\
\text { - Non-pancreatic malignancy } \\
\text { (e.g. Iymphoma, sarcoma) } \\
\text { - Coagulation disorder (e.g. } \\
\text { protein C or S deficiency, } \\
\text { factor V Leiden mutation, } \\
\text { myeloproliferative } \\
\text { disorders, thrombocytosis, } \\
\text { paroxysmal nocturnal } \\
\text { hemoglobinuria) } \\
\text { - Post-splenectomy and } \\
\text { other surgeries involving } \\
\text { the splenic vessels and } \\
\text { stomach } \\
\text { - Retroperitoneal fibrosis } \\
\text { - Abdominal trauma } \\
\text { - Splenic artery and vein } \\
\text { aneurysm } \\
\text { - Disseminated tuberculosis } \\
\text { - Idiopathic }\end{array}$ & $\begin{array}{l}\text { - Congenital } \\
\text { - Acquired } \\
\text { - Portal } \\
\text { hypertension } \\
\text { (e.g. secondary } \\
\text { to liver } \\
\text { cirrhosis) } \\
\text { - Inflammation } \\
\text { (e.g. } \\
\text { pancreatitis) } \\
\text { - Trauma } \\
\text { - Prior surgeries } \\
\text { - Idiopathic }\end{array}$ & $\begin{aligned} \text { - Congenital } \\
\text { - Acquired } \\
\text { - Portal hypertension } \\
\text { - Atherosclerosis } \\
\text { - Inflammation } \\
\text { (e.g. pancreatitis) } \\
\text { - Pregnancy } \\
\text { - Abdominal trauma } \\
\text { - Arterial degeneration } \\
\text { (e.g. medial } \\
\text { fibrodysplasia) } \\
\text { - Collagen vascular } \\
\text { disease } \\
\text { - Autoimmune disease } \\
\text { (e.g. systemic lupus } \\
\text { erythematosis, } \\
\text { polyarteritis nodosa) } \\
\text { - Post-liver transplant }\end{aligned}$ & $\begin{array}{l}\text { - Congenital } \\
\text { - Acquired } \\
\text { - Rupture of splenic } \\
\text { artery aneurysm into } \\
\text { corresponding } \\
\text { splenic vein } \\
\text { - Penetrating trauma } \\
\text { - Post-splenectomy, } \\
\text { gastrectomy } \\
\text { - Mycotic infection } \\
\text { - Pancreatitis } \\
\text { - Iatrogenic }\end{array}$ & $\begin{array}{l}\text { - Liver cirrhosis (e.g. } \\
\text { alcohol, hepatitis B, } \\
\text { hepatitis C, fatty } \\
\text { liver) } \\
\text { - Hepatocellular } \\
\text { carcinoma } \\
\text { - Antiphospholipid } \\
\text { antibodies } \\
\text { - Idiopathic } \\
\text { - Congenital } \\
\text { - Iatrogenic (e.g. } \\
\text { sclerotherapy } \\
\text { complication) }\end{array}$ \\
\hline
\end{tabular}


portography in the evaluation of the portal venous system, with a $93 \%$ sensitivity and $83 \%$ specificity. ${ }^{18}$ SVT will appear echogenic without detectable flow on Doppler US in cases of complete obstruction. Recently, Lewis et al. ${ }^{15}$ reported that endoscopic ultrasound (EUS) to diagnose SVT is superior to abdominal US and computed tomography (CT) for identifying pancreatic tumors and vascular involvement, with reported accuracies of $94 \%$ and $87 \%$, respectively. EUS should be considered in the evaluation for SVT and pancreatic disease, especially when other imaging modalities fail to identify SVT in spite of clinical signs in favor of that diagnosis. EUS is especially used when pancreatic disease or varices are suspected, or if patients are obese or have ascites.

CT scan with contrast may demonstrate SVT as an intraluminal low-density filling defect, together with splenomegaly, gastric or esophageal varices, and the underlying etiology. ${ }^{20}$ It has a $90 \%$ sensitivity and $50 \%$ specificity in identifying esophageal varices, and $87 \%$ sensitivity in diagnosing gastric varices. ${ }^{6,21}$ However, the preferred standard for the assessment of the portal venous anatomy is magnetic resonance angiography (MRA). SVT appears as an intraluminal filling defect after contrast administration. In a study by Edelman et al., ${ }^{22}$ MR angiography was found to be superior to abdominal US for identifying SVT, but the study was limited by a small population size. ${ }^{18,19,22,23}$

Moreover, as patients with SVT may initially present with GI bleeding, esophagogastroduodenoscopy (EGD) is also useful for identifying esophageal and gastric varices, and other sources of upper GI bleeding, with a reported accuracy of $90 \% .{ }^{18,20}$ Contrast barium examinations are now used only infrequently due to the superiority of more advanced diagnostic modalities. Endoscopically, gastric varices may appear as dilated veins or nodularities in the gastric rugae. ${ }^{18} \mathrm{~A}$ finding of isolated gastric varices should prompt further evaluation for possible left-sided portal hypertension. Pathology is not necessary for the diagnosis of SVT as imaging is usually sufficient. Fig. 1 shows a normal splenic artery (top image) and vein (center image), and a thrombosed splenic vein (bottom image).

\section{Treatment}

In the past, splenectomy was the treatment of choice for both symptomatic and asymptomatic SVT since blood flow to the collateral veins and gastric varices can be eliminated. However, in a meta-analysis by Butler et al., ${ }^{6}$ routine splenectomy for those without an overt GI bleed was not recommended, due to the high risk of portal or splenic vein thrombosis (PSVT) and post-operative infections. ${ }^{6,12}$ According to Krauth et al. ${ }^{16}$ there was an overall risk of 3.3\% for PSVT after open and laparoscopic splenectomy. However, Ikeda et al. ${ }^{17}$ identified a higher risk of PSVT among those who underwent laparoscopic compared to open splenectomy (55\% vs $19 \%$ ), possibly due to the pneumoperitoneum and laparoscopic splenectomy. This discrepancy highlights the need for larger prospective studies comparing the outcomes of both surgical techniques.

Alternatives to splenectomy that have been recently studied are associated with fewer complications and allow for preservation of the splenic structure and immune function. In a retrospective study on 11 patients with splenic vein occlusion and GI bleeding, Luo et al. ${ }^{13}$ described their experience using transjugular endovascular recanalization of the splenic vein, which led to resolution of the gastric varices.

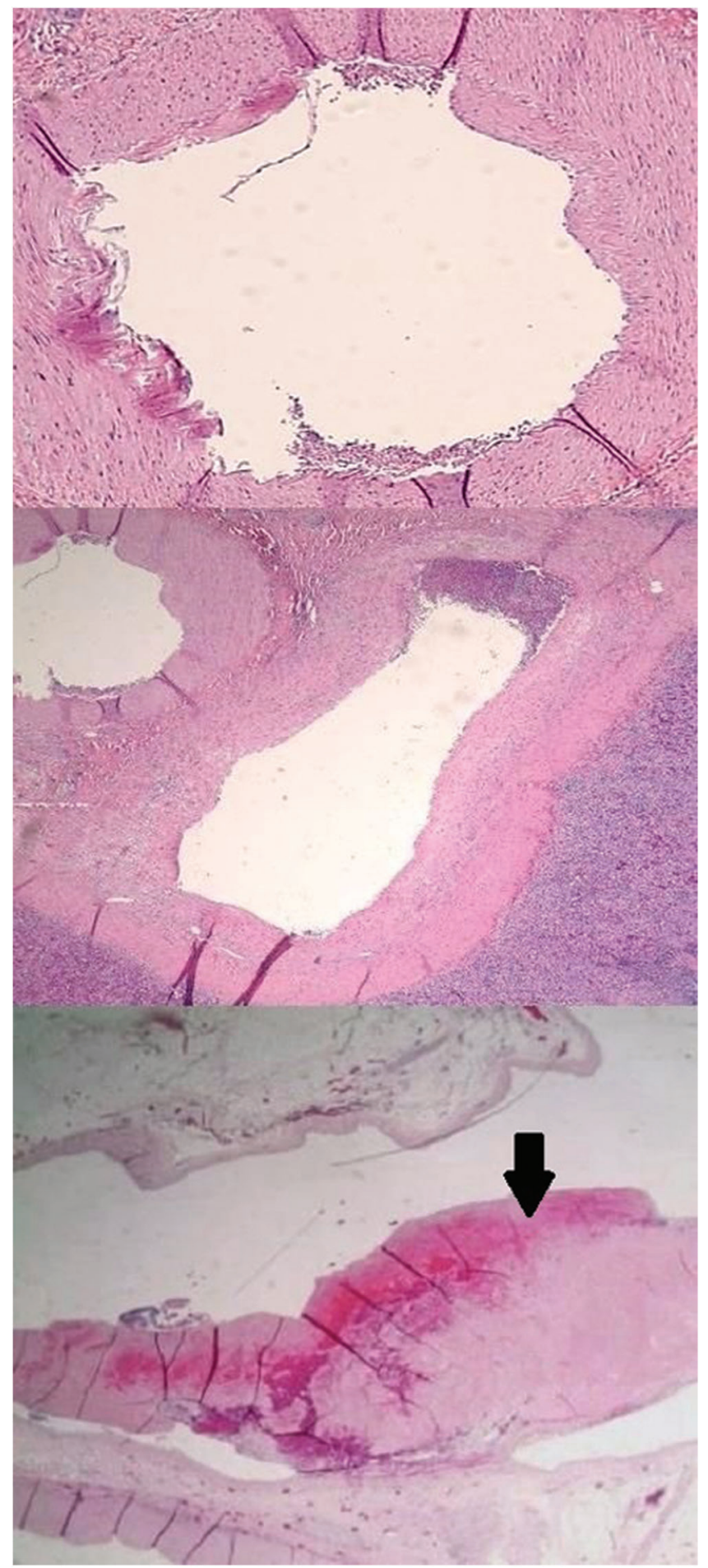

Fig. 1. Hematoxylin and Eosin (H\&E) stain of a section of a normal splenic artery (topmost image) and a normal splenic vein that are both $100 \times$ magnified (center image). An H\&E stain of a splenic vein with an organizing thrombus partially occluding the lumen (thrombus marked by the arrow), 100 $\times$ magnification is shown at the bottom image of Fig. 1.

There were no post-procedural complications or recurrence of the GI bleeding. However, stent stenosis was observed in $33 \%$ of the patients with bare metal stents on follow-up. ${ }^{13}$ 
A transhepatic approach was recommended for patients with cirrhosis because it involves creation of an intrahepatic portosystemic shunt. ${ }^{13}$ This study was limited by its short follow-up period of 3-34 months and small sample size.

Splenic artery embolization is another alternative to splenectomy. Wang et al. ${ }^{14}$ performed a retrospective study that included 14 patients with left-sided portal hypertension and gastric bleeding. A limited embolization of the splenic parenchyma was recommended due to the risk of splenic abscess with complete embolization. ${ }^{14}$ Although there was complete resolution of the gastric varices and collateral circulation, most patients developed post-embolization syndrome that included left upper quadrant pain and fever during follow-up. ${ }^{14}$ The role of anticoagulation in the treatment of SVT is still unclear. Its use has been reported in a few cases, as an adjunct to splenic vein revascularization and as sole treatment for SVT associated with malignancy or post-splenectomy. $9,12,17,24$ Given the recent advances in the management of SVT, treatment should be individualized, taking into account the surgical risk, severity of the GI bleeding, and the risks and benefits of each procedure.

\section{Splenic vein aneurysm}

Splenic vein aneurysm (SVA) is very rare, but there has been a reported increase in its occurrence, likely related to the increasing availability of advanced imaging modalities. In a systematic review by Sfyroeras et al., ${ }^{25}$ the reported incidence of SVA was $14.1 \%$ among the visceral venous aneurysms. SVA may be congenital or acquired, with most due to multifactorial causes. It may arise from a congenitally weak vessel wall or failure of the vitelline vein to regress, as evidenced by an antenatal diagnosis of SVA in a newborn. ${ }^{26}$ Although SVA occurs among those without liver disease, most authors still consider portal hypertension as the most common etiology of an acquired SVA since elevated portal pressure causes intimal thickening and medial hypertrophy, and subsequent fibrosis and aneurysm formation. 27,28 This association is supported by the regression of the SVA after decreasing portal venous pressure and splenic size. ${ }^{29}$ Other causes of SVA are listed in Table 1.25-32

Most SVA are incidental findings and are asymptomatic. According to Sfyroeras et al., ${ }^{25}$ abdominal pain is seen in $44.7 \%$ of patients with visceral venous aneurysms, followed by incidental discovery in $38.2 \%$, and GI bleeding in $7.3 \%$ of cases. Reported complications include thrombosis (in $17 \%$ of cases), splenic vein rupture (in $2.2 \%$ ), and obstructive jaundice from compression of adjacent structures like the duodenum and extrahepatic biliary ducts. ${ }^{25,26,28,31,32}$ Severe portal hypertension, coagulation disorder, and inflammation have been associated with rupture regardless of the aneurysm size. ${ }^{29,33}$ Whereas, thrombosis occurs from stagnation of blood flow in the dilated areas or due to compression of the vessel by surrounding structures.

\section{Diagnostics}

US is the initial imaging test of choice for diagnosing SVA, demonstrating either a saccular or fusiform, and hypo- or anechoic splenic vein dilatation. ${ }^{20,34-36}$ For extrahepatic portal vein aneurysms, which include SVAs (near its confluence with the superior mesenteric vein), a diameter that is greater than or equal to $2 \mathrm{~cm}$ is considered the diagnostic standard for cirrhotic patients, whereas it is at least $1.5 \mathrm{~cm}$ for the non-cirrhotic patients, based on the study by Doust and Pearce. ${ }^{37,38}$ The aneurysm will normally fill up with color flow at an increased flow velocity, with a "to-and-fro" flow or the "Yin-Yang sign" that signifies blood flow during systole and diastole. ${ }^{20,27,29,30,34-36}$

Currently, CT and magnetic resonance imaging (MRI) scans are often used as adjuncts when US results are equivocal or when complications are suspected. ${ }^{27,36,39}$ SVA will simultaneously enhance with the portal and superior mesenteric veins on CT, whereas they will appear as hypointense lesions on T1-weighted MRI. ${ }^{34}$ MRA is also a promising non-invasive tool that has replaced the conventional invasive angiography in the diagnosis of SVA, especially for patients undergoing surgery. ${ }^{39}$ Moreover, recent studies have demonstrated the utility of contrast-enhanced US in detecting SVA, as it has better delineation of the vessel lumen and patency, and configuration of the SVA when compared to the B mode and color flow US. ${ }^{36}$ However, this study was limited by a small sample size (7 patients) due to the rarity of these aneurysms. Its accuracy in diagnosing SVA needs to be verified in a larger study, with comparison to other diagnostic modalities. Lastly, pathology is not required for the diagnosis, but when available, histological findings include decrease in the number and size of elastic and muscle fibers of the wall, fragmented internal elastic layer, and replacement by fibrous tissue.

\section{Treatment}

If the patient is symptomatic, and when the aneurysm is significantly expanding or has complications, surgery is the treatment of choice. ${ }^{25,27,33,37,40,41}$ In a literature review by Laurenzi et al. ${ }^{37}$ involving 190 patients with portal vein aneurysms, $21 \%$ had surgery and post-operative mortality was noted to be $17.5 \%$. There were no reported recurrences of SVA, however most studies were limited by a short followup period (median of 10.5 months). ${ }^{37}$ The surgical therapies include aneurysmectomy with or without allograft placement, aneurysmorrhaphy with or without thrombectomy, splenectomy, and portal shunt procedures with splenectomy for those with portal hypertension. ${ }^{25,26,28,31,32,37}$ For patients without portal hypertension, aneurysmorrhaphy is the procedure of choice for those with saccular aneurysm, whereas aneurysmectomy is recommended for those with the fusiform type. 27,35

Currently, there is no general consensus regarding treatment of asymptomatic SVA. Some authors recommend serial monitoring of patients who are high-risk surgical candidates and without any portal hypertension and thrombosis, while others propose prophylactic surgery for low-risk surgical candidates. ${ }^{27-30}$ According to Moreno et al., ${ }^{40}$ surgery is recommended for asymptomatic SVA that is at least $3 \mathrm{~cm}$ in diameter, whereas serial observation is indicated for asymptomatic patients with an SVA diameter of less than $3 \mathrm{~cm}$. Even though studies have reported that bigger SVAs have higher rates of complications, such as thrombosis, rupture and compression of surrounding structures, there are still few reported cases of rupture that had an SVA diameter of less than $2 \mathrm{~cm} .{ }^{33}$ In a study by Sfyroeras et al., ${ }^{25}$ among the cases that were serially monitored, $94 \%$ of aneurysms were stable in terms of size on follow-up. There was only one reported case that demonstrated spontaneous regression of the SVA after years of observation, ${ }^{32}$ while some regressed with resolution of portal hypertension and splenomegaly, ${ }^{29}$ or remained stable with beta-blocker treatment. ${ }^{42}$ Due to the 


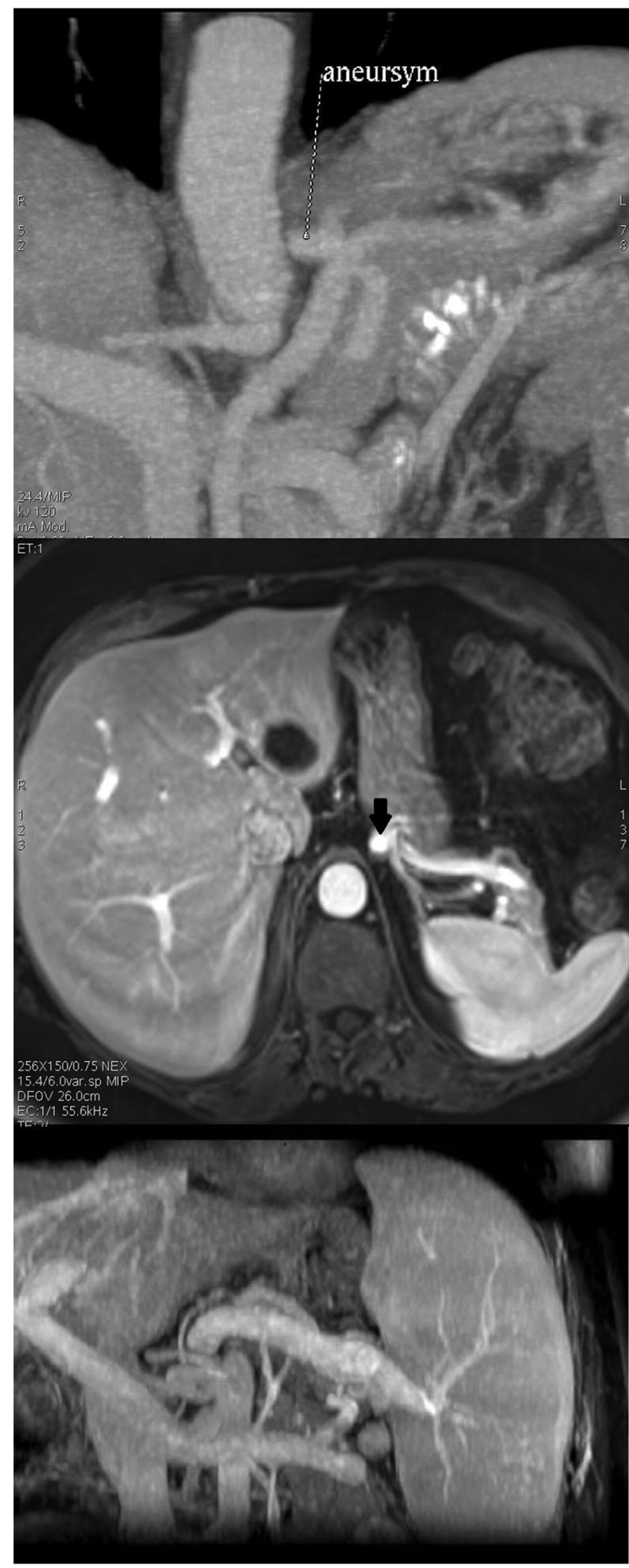

Fig. 2. Splenic artery aneurysm as seen on a CT scan of the abdomen under maximum intensity projection (MIP) (topmost image), a splenic artery aneurysm on MRI of the abdomen with contrast (marked by the arrow) (center image), and a spontaneous splenorenal shunt as seen in a CT scan of the abdomen with contrast (bottom image). significant post-operative mortality rate, management of asymptomatic SVA should be individualized, and should take into account the risk and benefits of surgery versus close follow-up with serial imaging.

\section{Splenic artery aneurysm/pseudoaneurysm}

Splenic artery aneurysm (SAA) is an abnormally dilated splenic artery, measuring more than $1 \mathrm{~cm}$ in diameter. Only a few reported cases of SAA have measured more than $10 \mathrm{~cm}$ in diameter, and these are known as giant SAAs. It is a true aneurysm and accounts for $60 \%$ of SAAs, with an overall incidence of $0.8 \% .{ }^{43-47}$ It affects females four-times more often than males ${ }^{43-45}$ and is often seen in the fifth and sixth decades of life. ${ }^{48}$ In large retrospective case series, the most frequent comorbidities among SAA patients have included hypertension (47-52\%), hyperlipidemia (44-47\%), and tobacco use (11-47\%), which highlights the role of atherosclerosis in the development of SAA. ${ }^{45-47}$ In another series involving 34 patients with SAA, 59\% had portal hypertension and had an associated mortality rate of $56 \%$, compared to the $17 \%$ without portal hypertension. ${ }^{49}$ Other causes of SAA are listed in Table $1 .{ }^{43-47}$ In contrast, splenic artery pseudoaneurysm involves a focal disruption of the vessel wall. It is less prevalent than true SAA, and occurs more often in males than in females. ${ }^{43}$ In a case series by Tessier et al., ${ }^{44}$ splenic artery pseudonaneurysm accounted for $27 \%$ of the visceral artery pseudoaneurysms. These were due to chronic pancreatitis $(46 \%)$, trauma $(29 \%)$, and unknown etiology $(13 \%) .{ }^{43,44}$ Most patients, however, had chronic alcohol use.

Most of the SAA are incidentally diagnosed, since $80-97.5 \%$ are asymptomatic. ${ }^{43,50}$ Symptomatic patients will present with nonspecific manifestations, like epigastric or left upper quadrant pain (49\%), nausea and vomiting, and anorexia. ${ }^{50}$ According to Mattal et al. ${ }^{46}$ spontaneous rupture of the SAA was the initial symptom of $2-10 \%$ of patients, with higher rates of rupture for giant SAA (28\%). They present with sudden-onset sharp abdominal pain, Kehr sign (left shoulder pain), GI bleeding and hemodynamic instability. ${ }^{43-46}$ Bleeding may also result from fistulization of an SAA into adjacent organs. ${ }^{43-46}$ Pseudoaneurysms also manifest with bleeding with $58 \%$ of patients being hemodynamically unstable on presentation. ${ }^{44}$ The "double rupture" phenomena, which is noted in $20-30 \%$ of ruptured SAA, is characterized by bleeding into the lesser sac with a temporary tamponade, followed by bleeding into the peritoneal cavity via the foramen of Winslow or rupture of pars flaccida within 48 hours. ${ }^{43,44}$ Most SAA ruptures occur in pregnancy ( $95 \%$ ) with a maternal-fetal mortality rate of $75 \%$, whereas the mortality rate of ruptured pseudoaneurysm is almost $100 \% .{ }^{43-45}$ Notable risk factors associated with rupture include a diameter of more than $2 \mathrm{~cm}$, pregnancy (especially during the third trimester), symptomatic SAA, portal hypertension and liver transplantation. ${ }^{47-49}$ Interestingly, in the study by Lakin et al. ${ }^{45}$ patients who initially presented with signs of rupture were less than 60 years old (39\%). An inverse relationship between the amount of calcification and the size of the aneurysm was found. It is still unclear if the calcification is protective against rupture or increasing growth of the aneurysm.

\section{Diagnostics}

SAA are frequently diagnosed incidentally, evidenced by a ring-like calcification in the left upper quadrant of a plain 
abdominal radiograph. ${ }^{20}$ However, for pregnant patients, US is often used due to its lack of radiation exposure. It will exhibit an anechoic mass, with or without calcification along its periphery, and with its vascularity emphasized by a color Doppler. ${ }^{20}$ US is less useful for small diameter aneurysms, however. ${ }^{43}$ An enhancing hypoattenuated mass, with or without peripheral calcification, may be demonstrated in the CT scan (Fig. 2, top image), with extravasation of contrast in cases of aneurysm rupture. ${ }^{20}$ On MRI (Fig. 2, center image), SAA will appear as a well-defined circular area with low signal intensity at the periphery and a varying signal intensity within the aneurysm, depending on the velocity of the blood flow and thrombus formation. ${ }^{20}$

Digital subtraction angiography (DSA) is the standard imaging method of choice for both SAA and pseudoaneurysm as it allows the determination of the exact location of the aneurysm and source of bleeding, and the detection of collateral circulation and concomitant intra-abdominal aneurysm. ${ }^{20,43}$ More importantly, it also permits therapeutic intervention by transcatheter embolization. ${ }^{20,43}$ In a recent prospective study by Ulu et al., ${ }^{51}$ multidetector CT angiography (MDCTA) was shown to be as accurate as DSA in the detection of SAA among children with chronic liver disease, representing a potential non-invasive alternative to DSA. For splenic artery pseudoaneurysm, US and CT scan, including CT angiography and MRA are not often used since they do not permit therapeutic interventions to be done concomitantly. ${ }^{20,43}$ In any case, a finding of pseudoaneurysm must be treated urgently because the risk of rupture is close to $100 \%$. Lastly, histological examination of SAA usually reveals subendothelial thickening, elastic lamina fragmentation, fibrosis and accumulation of glycosaminoglycans within the subintima and media. Secondary changes like luminal thrombosis and atherosclerosis can also be seen.

\section{Treatment}

Asymptomatic patients with SAA measuring more than $2 \mathrm{~cm}$ in diameter, or increasing in size must be treated. ${ }^{43-45}$ SAA detected among patients who are pregnant or are planning to become pregnant, and pre- or post-liver transplant, regardless of size, must also be treated due to the higher risk of rupture. ${ }^{43-45}$ Symptomatic patients with SAA require urgent treatment, whereas rupture necessitates emergent management. In a study by Lee et al. ${ }^{49}$ elective surgery had zero operative mortality compared to the $40 \%$ with emergent surgery from SAA rupture. Survival after 46 months of follow-up was noted to be $84 \%$ after elective repair, in contrast to the $60 \%$ after SAA rupture. ${ }^{49}$

Laparoscopic surgery, endovascular embolization and stent graft application have largely replaced open surgery (aneurysm ligation with or without splenectomy), which used to be the gold standard for the treatment of SAA. These procedures are less invasive and associated with lower periand post-procedural morbidity, faster recovery and shorter hospital stay. Conventional surgery is now mostly indicated for SAA rupture, especially with hemodynamic instability, due to its high morbidity rate of $9 \%$ to $25 \%$ and mortality rate of $1 \%$ to $3 \%{ }^{43-45}$ Conventional surgery approaches include splenectomy with aneurysmectomy for SAA deep in the hilum, partial splenectomy for distal SAA, trans-aneurysmal arterial ligation, and proximal and distal splenic artery ligation with or without aneurysmectomy. ${ }^{43}$ Splenic conservation should be the goal for more proximal SAA. Surgery may be done via the lateral approach, which preserves the spleen's collateral circulation, or via the anterior approach, which increases the risk of splenic infarction. ${ }^{43}$

In a prospective study conducted by Tiberio et al. ${ }^{52}$ involving 29 SAA patients who were randomized to either laparoscopy or laparotomy, the laparoscopy group had lower morbidity rates, shorter hospital stays and more rapid recoveries. The $13.3 \%$ conversion rate from laparoscopic to open surgery was due to concomitant involvement of the pancreatic tail, and iatrogenic vessel tear during dissection. ${ }^{52}$ Although, it was reported that laparoscopic repair cannot be done in cases of an SAA rupture, Kim et al. ${ }^{53}$ was able to successfully repair a ruptured SAA laparoscopically. Recent literature reviews also illustrate that laparoscopic surgery with splenectomy and possible distal pancreatectomy can be performed for hilar SAA that are difficult to manage using endovascular treatment. ${ }^{54}$

Transcatheter embolization is preferred by most physicians as the initial treatment for asymptomatic SAA, especially among high-risk patients and surgically difficult SAA, except for those located in the splenic hilum, which requires splenectomy. ${ }^{43-45}$ The reported success rates range from $85-100 \%$. The speed and non-invasiveness of the procedure allows for the preservation of the spleen and its immunologic functions. ${ }^{43-45}$ Notable complications include abscess, migration of the coil and subsequent distal infarction, rupture, recanalization, and post-embolization syndrome manifesting with abdominal pain, fever, leukocytosis, thrombocytopenia and elevated lipase. ${ }^{43-47}$ In addition, endovascular stenting has been also used recently for proximal aneurysms due its lower risk of infarction and ability to preserve the splenic circulation. ${ }^{43}$ The successful treatment of SAA rupture by endovascular surgery has been documented in a few cases, especially on patients with portal hypertension because surgery is more technically difficult given the extensive collateral circulation. ${ }^{43,50,55,56}$ Other newer treatment options include staged therapy that involves embolization followed by surgical excision, and laparoscopic robotic surgery. ${ }^{43-45}$

Conservative management is preferred for asymptomatic SAA that measures greater than $2 \mathrm{~cm}$ in diameter. According to Lakin et al., ${ }^{45}$ patients who were observed with serial CT scan every 6 months showed a mean increase of $0.2 \mathrm{~mm} /$ year in the diameter of the aneurysm over a follow-up period of 3 years. Because there were no reported ruptures or mortalities in the observed group, the authors concluded that small (less than $2 \mathrm{~cm}$ ), asymptomatic, and heavily calcified SAA can be effectively managed with serial imaging due to a negligible risk of rupture. ${ }^{45}$ Due to the retrospective nature of this study and lack of randomization, it is prone to possible selection and treatment bias. However, it is still one of the largest cases series, as it included 128 patients with SAA. Up until now, there is no general consensus regarding the appropriate duration of follow-up for previously treated patients or those managed conservatively. Nonetheless, post-liver transplant patients should be monitored for SAA all throughout their lives. SAA has an excellent prognosis with timely intervention, since the 10 -year survival rate in the treatment group is $85.1 \%$, compared to the $94.9 \%$ rate in the observation group. ${ }^{45}$

In a large meta-analysis by Hogendoorn et al. ${ }^{48}$ involving 1321 patients with SAA, endovascular surgery was noted to have better short-term outcomes and a lower perioperative mortality rate, when compared to open surgery. However, open surgery was associated with lower rate of late 
Uy P.P.D. et al: Vascular diseases of the spleen

complications and re-interventions, while conservative management had a higher delayed morality rate which was thought to be related to the patients' multiple comorbidities. $^{48}$ Limitations of the study included the inclusion of mostly retrospective studies, the absence of laparoscopic surgery in the analysis, and missing information regarding the exact location of the SAA. Therefore, treatment of SAA must take into account the location and extent of the aneurysm, risk of rupture, surgical risk, and technical expertise. A prospective study that compares the efficacy and longterm outcomes of the different endovascular techniques with open and laparoscopic surgery is highly recommended. In contrast, pseudoaneurysms-regardless of symptoms and size-must be treated emergently due to a $100 \%$ risk of rupture. There is a high mortality rate of $50 \%$ if near the pancreatic body or tail, and $15 \%$ if near the pancreatic head. ${ }^{43}$ Endovascular surgery is the recommended treatment of choice. Complications include abdominal pain, splenic infarction and abscess, pancreatic abscess and death. ${ }^{43,44}$ Other therapeutic options include injection of thrombin-collagen complex and stent graft application, and splenectomy with distal pancreatectomy if associated with a pancreatic pseudocyst. ${ }^{43,44}$ Most importantly, post-procedural vaccination against encapsulated bacteria is important after splenectomy and after splenic treatments that are associated with risk for splenic infarction. ${ }^{43,56}$

\section{Splenic arteriovenous fistula}

Splenic arteriovenous fistula (SAVF) is rare and can either be congenital or acquired. According to Schmidt et al., ${ }^{57}$ congenital SAVF are intrasplenic and hemangiomatous, whereas acquired SAVF are secondary to traumatic, iatrogenic or spontaneous lesions. Other causes of SAVF are presented in Table $1 .^{57-62}$ It occurs more often in females (80\%), especially the multiparous, and its occurrence in men is likely associated to prior surgery or penetrating trauma. ${ }^{61}$ Only $16 \%$ of cases presented without signs of portal hypertension. ${ }^{59}$ SAVF should be considered in a patient with signs of acute portal hypertension that is not associated with a chronic liver disease. ${ }^{57-63}$ Most cases are asymptomatic, but the clinical suspicion increases whenever a characteristic "machinery bruit" is auscultated in the epigastric, left upper quadrant or left flank area in $30 \%$ to $60 \%$ of cases. ${ }^{57,58}$ These symptoms are secondary to the hyperdynamic blood flow state through the arteriovenous shunt, which leads to the sudden increase in pressure and congestion within the portal and mesenteric venous system. ${ }^{57,58}$ Other clinical manifestations of SAVF are enumerated on Table 2. ${ }^{57-63}$ Untreated SAVF will eventually lead to portal hypertension and variceal bleeding, and intrahepatic sclerosis which causes irreversible portal hypertension that persists despite treatment. ${ }^{45,63}$

\section{Diagnostics}

US with color Doppler is the initial imaging of choice because it is non-invasive and inexpensive, and can document the presence of SAVF, portal hypertension and splenomegaly, and exclude hepatic parenchymal disease. ${ }^{57-63}$ There is a turbulent and pulsatile blood flow with increased velocity within the fistula and immediately distal to it, together with a dilated and elongated afferent splenic artery and draining splenic vein. ${ }^{20,63}$ SAVF will enhance early with contrast-enhanced CT and MRI scan, and MR and CT angiography. ${ }^{20,59}$ However, selective celiac or splenic arteriography is still the gold standard imaging for SAVF because of its high accuracy in localizing the vessel abnormality and collateral circulation, and it also allows the performance of embolization procedures concomitantly. ${ }^{58}$ It will appear as a tortuous splenic artery and a dilated splenic vein that fills early during the arterial phase. ${ }^{20,61}$ This invasive imaging is especially recommended for patients with acute portal hypertension, and machinerylike abdominal bruit, in the absence of chronic liver disease. ${ }^{58}$ Although angiography is still the gold standard, Doppler ultrasonography allows a rapid diagnosis especially during medical emergencies presenting with massive GI bleeding.

\section{Treatment}

SAVF is highly curable, and early diagnosis and treatment are keys to preventing complications from portal hypertension. Currently, percutaneous arterial embolization is the treatment of choice for SAVF since it is less invasive, less costly, less risky and more rapidly performed with preservation of the spleen and its immunologic function. ${ }^{57-65}$ Complications include splenic infarction, abscess or rupture and risks are higher with complete ablation compared to segmental ablation. ${ }^{65}$ Open surgery is now reserved for patients with complications, chronic kidney disease, or with failure of embolization. ${ }^{59}$ It may either be by surgical ligation or resection of the fistula with aneurysmorrhaphy or splenectomy. ${ }^{61}$ With advances of endovascular procedures, studies have found that open surgery is more technically difficult and has a higher failure rate due to the distal location of the fistula and the possible collateral circulation and adhesions adjacent to it. ${ }^{58}$ Another alternative treatment that is mentioned in case reports include endovascular stent graft application for those without a tortuous splenic artery. ${ }^{64}$

\section{Spontaneous splenorenal shunt}

Spontaneous splenorenal shunt (SSRS) is a porto-systemic shunt that is mostly seen in patients with liver cirrhosis and portal hypertension. ${ }^{66}$ However, there are cases of SSRS among non-cirrhotic patients presenting with hyperammonemia and chronic recurrent hepatic encephalopathy. According to several studies, the prevalence of SSRS among liver cirrhosis patients ranges from $18.5 \%$ to $21 \%$, with greater occurrence among those with hepatocellular carcinoma (HCC) and increasing body mass index, possibly related to the increased risk of HCC among obese people. ${ }^{67,68}$ It is still unclear whether the presence of SSRS is associated with the severity of cirrhosis due to conflicting study results. von Herbay et al. ${ }^{68}$ noted increasing prevalence of SSRS among Child-Pugh grade $B$ and $C$ patients, whereas the study by Tarantino et al. ${ }^{67}$ did not show any relationship. Other causes of SSRS are presented in Table 1.66-71

In direct SSRS, there is communication between the exorenal circle and splenic vein tributaries at the fusion fascia of Toldt, which is the adhesion fascia of the visceral peritoneum and mesentery. ${ }^{66}$ SSRS was thought to be from the recanalization or reopening of embryonic channels that were closed during normal hemodynamics due to increase in resistance to portal outflow with portal hypertension, and also by the influence of vasoactive substances like nitric oxide and vascular endothelial growth factors that increases blood flow to the splanchnic circulation. ${ }^{66,67}$ SSRS may be incidentally diagnosed by imaging patients with liver cirrhosis and 


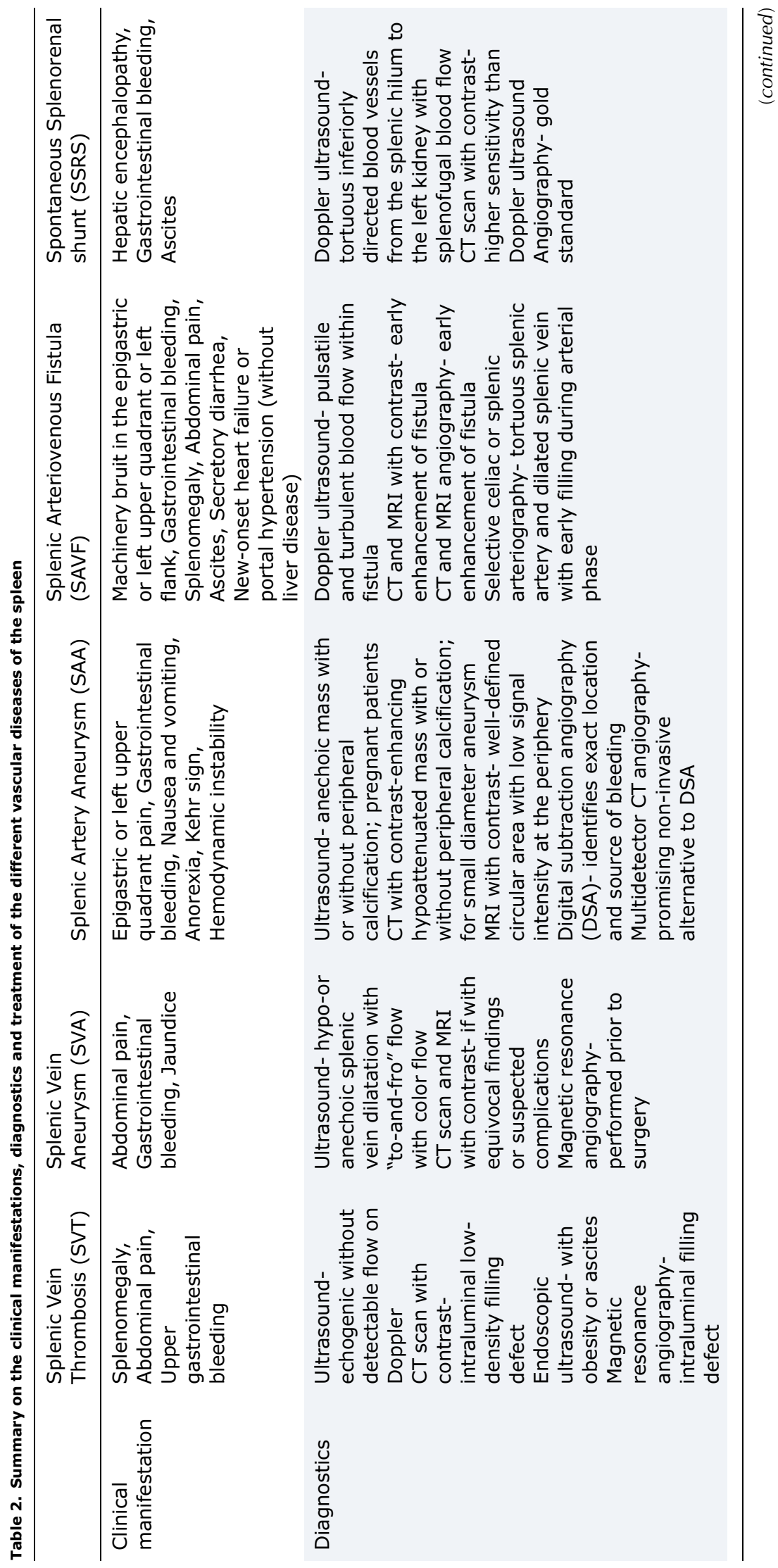




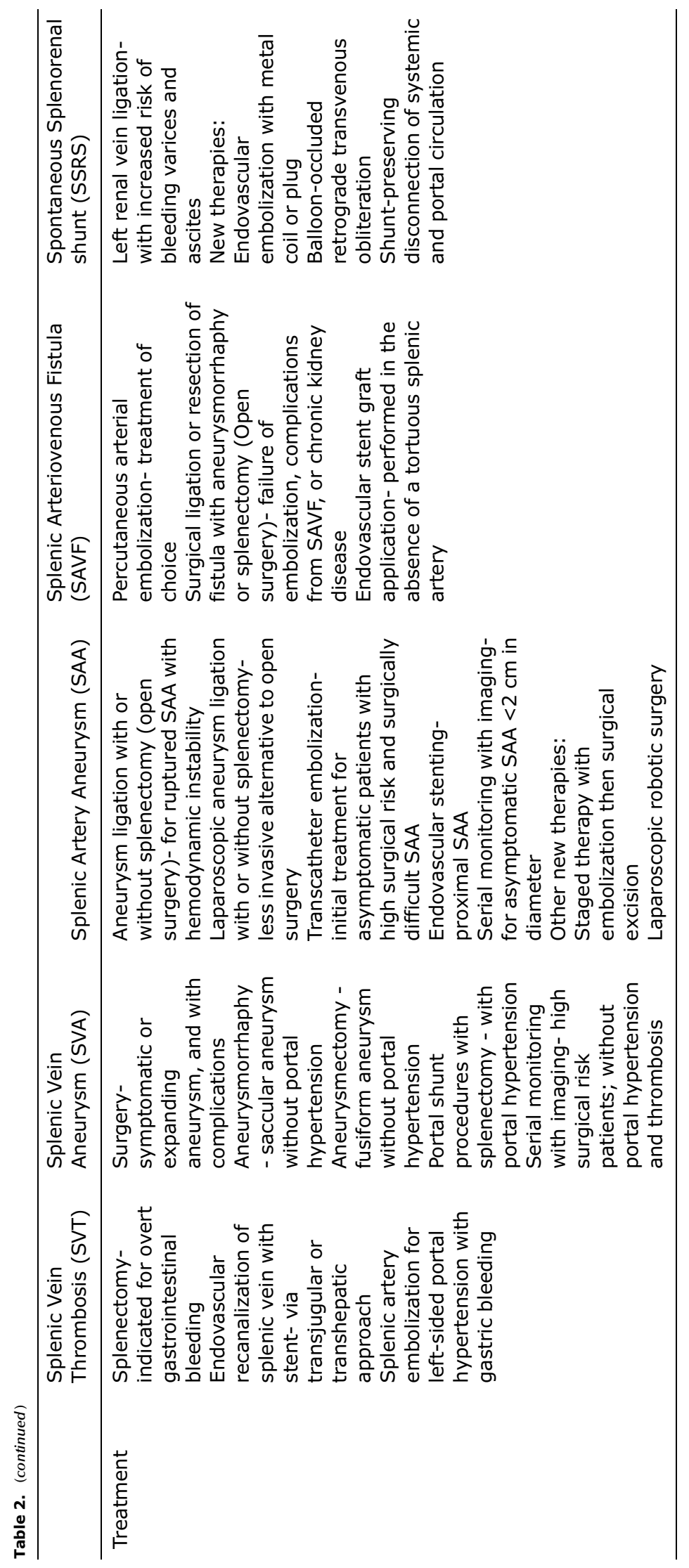


signs of portal hypertension, and on further work-up among patients without signs of liver cirrhosis, but with hyperammonemia and signs of hepatic encephalopathy. ${ }^{66-68}$ In a large case series involving 109 patients with liver cirrhosis, 50\% of the patients with esophageal varices had some form of intra-abdominal porto-systemic shunt, whereas only $13 \%$ of those without varices had shunts. ${ }^{68}$ In the same study, there was also a positive correlation between the presence of shunts and ascites (61\% versus $39 \%$ ), and portal vein thrombosis. ${ }^{68}$ However, there was no significant correlation between the presence of these shunts and splenomegaly. ${ }^{68}$ These findings are in contrast to most reports of fewer varices and less ascites in the presence of these portosystemic shunts by spontaneous decompression of the portal pressure. SSRS is associated with increasing intestinal sepsis, and chronic, recurrent and refractory porto-systemic encephalopathy. ${ }^{69}$

\section{Diagnostics}

Doppler US is often the initial imaging tool used to diagnose liver cirrhosis and it allows a non-invasive diagnosis of portosystemic shunts by detecting the direction of the portal blood flow. ${ }^{67,68}$ SSRS will appear as tortuous inferiorly directed blood vessels originating from the splenic hilum to the left kidney with evidence of splenofugal blood flow and markedly increased splenic volume, dilated left renal vein with phasic blood flow at a velocity of greater than $20 \mathrm{~cm} / \mathrm{sec}$, and dilated splenic vein (greater than $5 \mathrm{~mm}$ ) with phasic blood flow at a velocity of greater than $15 \mathrm{~cm} / \mathrm{sec} .{ }^{67}$ In a comparative study by Bagheri et al., ${ }^{72}$ CT scan (Fig. 2, bottom image) had a $78.6 \%$ sensitivity and $67.9 \%$ specificity in the diagnosis of SSRS while Doppler US had a sensitivity of $66.7 \%$ and a specificity of $85.7 \%$. This implies that CT scan must be performed despite a negative finding on US due to its low sensitivity.

Angiography or portography is still considered the gold standard but its invasiveness and cost makes it less suitable for initial use or close follow-ups. ${ }^{67}$ Other diagnostic tests that have been used to document SSRS include MRI, single photon emission $\mathrm{CT}^{67}$ It is important to screen liver transplant patients for the presence of spontaneous porto-systemic shunts in order to increase the chance of graft survival and reduce the risk of post-transplant portal vein thrombosis, as the presence of these shunts decreases portal blood flow. ${ }^{2-74}$

\section{Treatment}

SRSS was previously treated by left renal vein ligation which rapidly decreased the blood ammonia levels and improved the encephalopathy. ${ }^{73-76}$ However, there was a noted increase in the risk of bleeding varices and ascites by increasing the portal blood flow. Due to the significant postoperative morbidity and mortality risk with conventional surgical ligation, newer treatment modalities are now utilized and these include endovascular embolization with a metal coil or plug, balloon-occluded retrograde transvenous obliteration, and shunt-preserving disconnection of the systemic and portal circulation. ${ }^{73-76} \mathrm{~A}$ comparative study of the long-term outcomes and efficacy of these different therapeutic options is needed. Lastly, Table 2 outlines and compares the clinical manifestations, diagnostics, and treatments of the 5 major types of splenic vascular diseases, and Fig. 3 and 4 demonstrate schematic diagrams of the structures of the spleen that illustrate the typical abnormality of each disease.
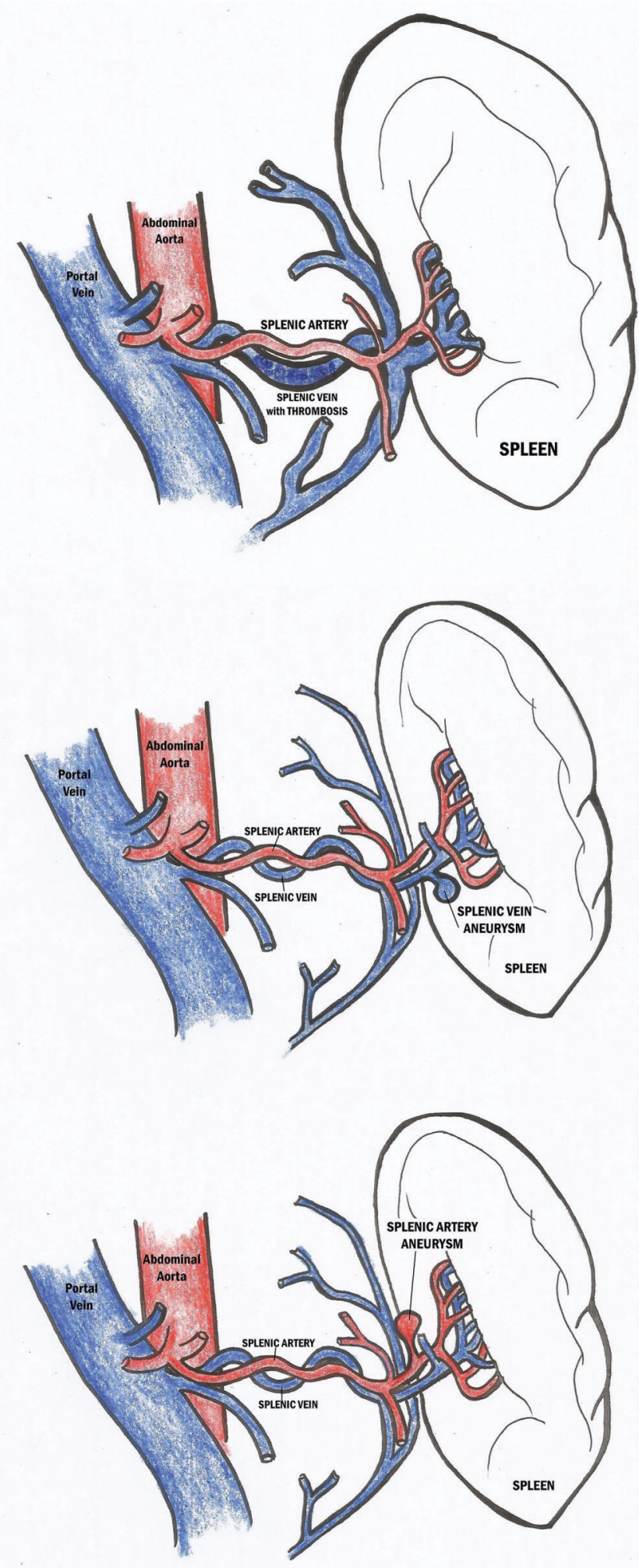

Fig. 3. Schematic diagrams of a splenic vein thrombosis with associated splenomegaly (topmost image), splenic vein aneurysm (center image), and a splenic artery aneurysm (bottom image). 
Uy P.P.D. et al: Vascular diseases of the spleen

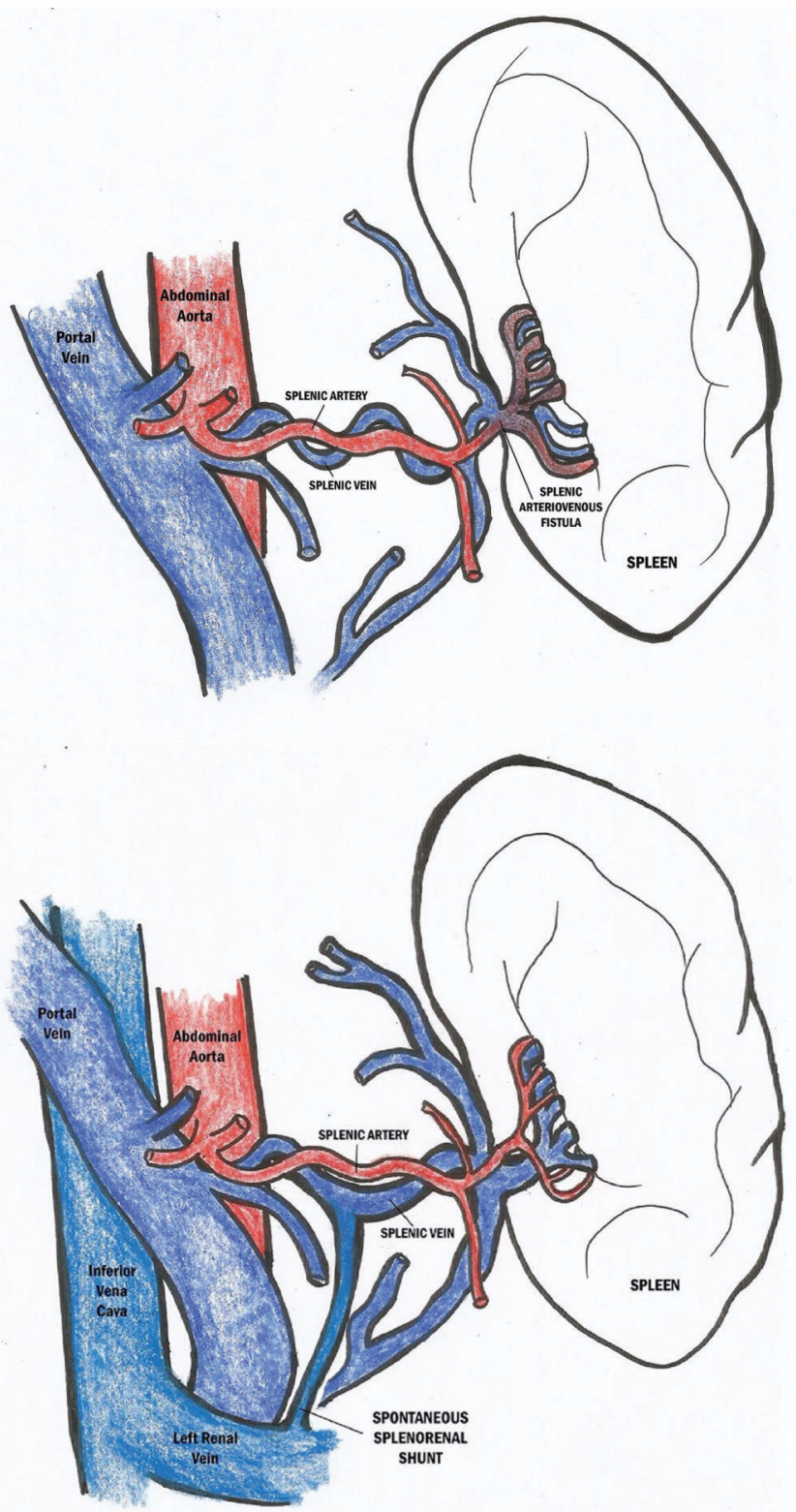

Fig. 4. Schematic diagrams of a splenic arteriovenous fistula (top image) and a spontaneous splenorenal shunt connecting the splenic vein and left renal vein (bottom image).

\section{Acknowledgement}

The support of the Herman Lopata Chair in Hepatitis Research to GY Wu is gratefully acknowledged.

\section{Conflict of interest}

The authors have no conflict of interests related to this publication.

\section{Author contributions}

Conceived the topic (PPDU, GYW), prepared the manuscript (PPDU), generated the schematic diagrams (DMF), contributed to the pathology and radiology section (AT, MO'L), edited the manuscript (GYW). All the authors made significant contributions to this review article.

\section{References}

[1] Moore KL, Dalley AF II, Agur AMR. Abdomen. In: Clinically Oriented Anatomy. $7^{\text {th }}$ ed. Lippincott Williams \& Wilkins, 2014:263-265.

[2] Drake RL, Vogl AW, Mitchell AW. Abdominal viscera. In: Gray's Anatomy for Students. $3^{\text {rd }}$ ed. Philadelphia: Churchill Livingstone, 2015:346-355.

[3] Wilkins BS, Wright DH. Normal Structure, Development and Functions of the Spleen. In: Illustrated Pathology of the Spleen. United Kingdom: Cambridge University Press, 2000:13-16.

[4] Weber SM, Rikkers LF. Splenic vein thrombosis and gastrointestinal bleeding in chronic pancreatitis. World J Surg 2003;27:1271-1274. doi: 10.1007/ s00268-003-7247-6.

[5] Agarwal AK, Raj Kumar K, Agarwal S, Singh S. Significance of splenic vein thrombosis in chronic pancreatitis. Am J Surg 2008;196:149-154. doi: 10. 1016/j.amjsurg.2007.07.039.

[6] Butler JR, Eckert GJ, Zyromski NJ, Leonardi MJ, Lillemoe KD, Howard TJ. Natural history of pancreatitis-induced splenic vein thrombosis: a systematic review and meta-analysis of its incidence and rate of gastrointestinal bleeding. HPB (Oxford) 2011;13:839-845. doi: 10.1111/j.1477-2574. 2011.00375.x.

[7] Sutton JP, Yarborough DY, Richards JT. Isolated splenic vein occlusion. Review of literature and report of an additional case. Arch Surg 1970;100:623-626. doi: 10.1001/archsurg.1970.01340230089024.

[8] Tan KG, Roberts-Thomson IC. Images of interest. Hepatobiliary and pancreatic: splenic vein thrombosis. J Gastroenterol Hepatol 2005;20:1944. doi: 10.1111/j.1440-1746.2005.04188.x.

[9] McIntyre B, Marsh M, Walden J. Puzzles in practice: splenic vein thrombosis. Postgrad Med 2016;128:538-540. doi: 10.1080/00325481.2016.1185922.

[10] Simpson WG, Schwartz RW, Strodel WE. Splenic vein thrombosis. South Med J 1990;83:417-421. doi: 10.1097/00007611-199004000-00014.

[11] Jain D, Verma K, Jain P. Disseminated tuberculosis causing isolated splenic vein thrombosis and multiple splenic abscesses. Oxf Med Case Reports 2014; 2014:107-109. doi: 10.1093/omcr/omu042.

[12] Ghelfi J, Thony F, Frandon J, Rodiere M, Leroy V, Vendrell A. Gastrointestinal bleeding due to pancreatitis-induced splenic vein thrombosis: Treatment with percutaneous splenic vein recanalization. Diagn Interv Imaging 2016; 97:677-679. doi: 10.1016/j.diii.2016.01.005.

[13] Luo X, Nie L, Wang Z, Tsauo J, Tang C, Li X. Transjugular endovascular recanalization of splenic vein in patients with regional portal hypertension complicated by gastrointestinal bleeding. Cardiovasc Intervent Radiol 2014;37: 108-113. doi: 10.1007/s00270-013-0625-z.

[14] Wang $Q$, Xiong B, Zheng C, Liang M, Han P. Splenic arterial embolization in the treatment of severe portal hypertension due to pancreatic diseases: the primary experience in 14 patients. Cardiovasc Intervent Radiol 2016;39: 353-358. doi: 10.1007/s00270-015-1199-8.

[15] Lewis JD, Faigel DO, Morris JB, Siegelman ES, Kochman ML. Splenic vein thrombosis secondary to focal pancreatitis diagnosed by endoscopic ultrasonography. J Clin Gastroenterol 1998;26:54-56. doi: 10.1097/00004836199801000-00014.

[16] Krauth MT, Lechner K, Neugebauer EA, Pabinger I. The postoperative splenic/portal vein thrombosis after splenectomy and its prevention-an unresolved issue. Haematologica 2008;93:1227-1232. doi: 10.3324/haematol. 12682.

[17] Ikeda $M$, Sekimoto $M$, Takiguchi S, Kubota M, Ikenaga $M$, Yamamoto $H$, et al. High incidence of thrombosis of the portal venous system after laparoscopic splenectomy: a prospective study with contrast-enhanced CT scan. Ann Surg 2005;241:208-216. doi: 10.1097/01.sla.0000151794.28392.a6.

[18] Köklü S, Coban S, Yüksel O, Arhan M. Left-sided portal hypertension. Dig Dis Sci 2007;52:1141-1149. doi: 10.1007/s10620-006-9307-x.

[19] Köklü S, Yüksel O, Arhan M, Coban S, Başar O, Yolcu OF, et al. Report of 24 left-sided portal hypertension cases: a single-center prospective cohort study. Dig Dis Sci 2005;50:976-982. doi: 10.1007/s10620-005-2674-x.

[20] Vanhoenacker FM, Op de Beeck B, De Schepper AM, Salgado R, Snoeckx A, Parizel PM. Vascular disease of the spleen. Seminars in Ultrasound, CT and MR 2007;28:35-51. doi: 10.1053/j.sult.2006.10.006.

[21] Perri RE, Chiorean MV, Fidler JL, Fletcher JG, Talwalkar JA, Stadheim L, et al. A prospective evaluation of computerized tomographic (CT) scanning as a screening modality for esophageal varices. Hepatology 2008;47: 1587-1594. doi: 10.1002/hep.22219.

[22] Edelman RR, Zhao B, Liu C, Wentz KU, Mattle HP, Finn JP, et al. MR angiography and dynamic flow evaluation of the portal venous system. AJR Am J Roentgenol 1989;153:755-760. doi: 10.2214/ajr.153.4.755. 
[23] Elsayes KM, Narra VR, Mukundan G, Lewis JS Jr, Menias CO, Heiken JP. MR imaging of the spleen: spectrum of abnormalities. Radiographics $2005 ; 25$ : 967-982. doi: 10.1148/rg.254045154.

[24] Wu Z, Zhou J, Pankaj P, Peng B. Comparative treatment and literature review for laparoscopic splenectomy alone versus preoperative splenic artery embolization splenectomy. Surg Endosc 2012;26:2758-2766. doi: 10.1007/ s00464-012-2270-z.

[25] Sfyroeras GS, Antoniou GA, Drakou AA, Karathanos C, Giannoukas AD. Visceral venous aneurysms: clinical presentation, natural history and their management: a systematic review. Eur J Vasc Endovasc Surg 2009;38: 498-505. doi: 10.1016/j.ejvs.2009.05.016.

[26] Gomez R, Bentsen DM, Burd RS. Antenatal diagnosis of an extrahepatic portal vein aneurysm. South Med J 2004;97:1023-1024. doi: 10.1097/01. SMJ.0000141307.19657.5E.

[27] Ma R, Balakrishnan A, See TC, Liau SS, Praseedom R, Jah A. Extra-hepatic portal vein aneurysm: A case report, overview of the literature and suggested management algorithm. Int J Surg Case Rep 2012;3:555-558. doi: 10.1016/j.ijscr.2012.07.009.

[28] Torres G, Hines GL, Monteleone F, Hon M, Diel J. Splenic vein aneurysm: is it a surgical indication? J Vasc Surg 1999;29:719-721. doi: 10.1016/S07415214(99)70320-4.

[29] Tolgonay G, Ozbek SS, Oniz H, Süzer E, Yurdakul LO. Regression of splenic vein aneurysm following resolution of splenomegaly. J Clin Ultrasound 1998 26:98-102. doi: 10.1002/(SICI)1097-0096(199802)26:2<98::AID-JCU9>3. $0 . \mathrm{CO} ; 2-\mathrm{D}$.

[30] Cömert M, Erdem LO, Ozdolap S, Erdem CZ, Sarikaya S. Splenic vein aneurysm demonstrated by magnetic resonance angiography. Dig Dis Sci 2005 . 50:1344-1346. doi: 10.1007/s10620-005-2785-4.

[31] Koc Z, Oguzkurt L, Ulusan S. Portal venous system aneurysms: imaging, clinical findings, and a possible new etiologic factor. AJR Am J Roentgenol 2007;189:1023-1030. doi: 10.2214/AJR.07.2121.

[32] Lall P, Potineni L, Dosluoglu HH. Complete spontaneous regression of an extrahepatic portal vein aneurysm. J Vasc Surg 2011;53:206-208. doi: 10. 1016/j.jvs.2010.07.063.

[33] Shimoda M, Kubota K, Sakuma A, Hogami T, Yamaguchi H, Tagaya N. Intraabdominal hemorrhage due to rupture of a splenic vein aneurysm: a case report. J Gastrointest Surg 2003;7:683-686. doi: 10.1016/S1091-255X(03) 00028-3.

[34] Atasoy KC, Fitoz S, Akyar G, Aytaç S, Erden I. Aneurysms of the portal venous system. Gray-scale and color Doppler ultrasonographic findings with CT and MRI correlation. Clin Imaging 1998;22:414-417. doi: 10.1016/ S0899-7071(98)00036-9.

[35] Brock PA, Jordan PH Jr, Barth MH, Rose AG. Portal vein aneurysm: a rare but important vascular condition. Surgery 1997;121:105-108. doi: 10.1016/ S0039-6060(97)90190-2

[36] Tana C, Dietrich CF, Badea R, Chiorean L, Carrieri V, Schiavone C. Contrastenhanced ultrasound in portal venous system aneurysms: a multi-center study. World J Gastroenterol 2014;20:18375-18383. doi: 10.3748/wjg. v20.i48.18375.

[37] Laurenzi A, Ettorre GM, Lionetti R, Meniconi RL, Colasanti M, Vennarecci G. Portal vein aneurysm: What to know. Dig Liver Dis 2015;47:918-923. doi: 10.1016/j.dld.2015.06.003.

[38] Doust BD, Pearce JD. Gray-scale ultrasonic properties of the normal and inflamed pancreas. Radiology 1976;120:653-657. doi: 10.1148/120.3.653.

[39] López-Machado $E$, Mallorquín-Jiménez F, Medina-Benítez A, Ruiz-Carazo $E_{\text {, }}$ Cubero-García M. Aneurysms of the Portal Venous System: Ultrasonography and CT findings. Aneurysms of the portal venous system: ultrasonography and CT findings. Eur J Radiol 1998;26:210-214. doi: 10.1016/S0720-048X (96)01146-1.

[40] Moreno JA, Fleming MD, Farnell MB, Gloviczki P. Extrahepatic portal vein aneurysm. J Vasc Surg 2011;54:225-226. doi: 10.1016/j.jvs.2010.05.113.

[41] Iimuro Y, Suzumura K, Ohashi K, Tanaka H, Iijima H, Nishiguchi S, et al. Hemodynamic analysis and treatment of an enlarging extrahepatic portal aneurysm: report of a case. Surg Today 2015;45:383-389. doi: 10.1007/ s00595-014-0882-8.

[42] Debernardi-Venon W, Stradella D, Ferruzzi G, Marchisio F, Elia C, Rizzetto M. Extrahepatic aneurysm of the portal venous system and portal hypertension. World J Hepatol 2013;5:149-151. doi: 10.4254/wjh.v5.i3.149.

[43] Al-Habbal Y, Christophi C, Muralidharan V. Aneurysms of the splenic artery - a review. Surgeon 2010;8:223-231. doi: 10.1016/j.surge.2009.11.011.

[44] Tessier DJ, Stone WM, Fowl RJ, Abbas MA, Andrews JC, Bower TC, et al. Clinical features and management of splenic artery pseudoaneurysm: case series and cumulative review of literature. J Vasc Surg 2003;38:969-974. doi: $10.1016 /$ S0741.

[45] Lakin RO, Bena JF, Sarac TP, Shah S, Krajewski LP, Srivastava SD, et al. The contemporary management of splenic artery aneurysms. J Vasc Surg 2011. 53:958-964; discussion 965. doi: 10.1016/j.jvs.2010.10.055.

[46] Mattar SG, Lumsden AB. The management of splenic artery aneurysms: experience with 23 cases. Am J Surg 1995;169:580-584. doi: 10.1016/ S0002-9610(99)80225-6.
[47] Pulli R, Innocenti AA, Barbanti E, Dorigo W, Turini F, Gatti M, et al. Early and long-term results of surgical treatment of splenic artery aneurysms. Am J Surg 2001;182:520-523. doi: 10.1016/S0002-9610(01)00744-9.

[48] Hogendoorn W, Lavida A, Hunink MG, Moll FL, Geroulakos G, Muhs BE, et al. Open repair, endovascular repair, and conservative management of true splenic artery aneurysms. J Vasc Surg 2014;60:1667-1676.e1. doi: 10. 1016/j.jvs.2014.08.067.

[49] Lee PC, Rhee RY, Gordon RY, Fung J], Webster MW. Management of splenic artery aneurysms: the significance of portal and essential hypertension. J Am Coll Surg 1999;189:483-490. doi: 10.1016/S1072-7515(99)00168-4.

[50] Abbas MA, Stone WM, Fowl R], Gloviczki P, Oldenburg WA, Pairolero PC, et al. Splenic artery aneurysms: two decades experience at Mayo clinic. Ann Vasc Surg 2002;16:442-449. doi: 10.1007/s10016-001-0207-4.

[51] Ulu EM, Kirbas I, Emiroglu FK, Cakir B, Harman A, Bakar C, et al. Multidetector CT findings of splenic artery aneurysm in children with chronic liver disease. Pediatr Radiol 2008;38:1095-1098. doi: 10.1007/s00247-0080976-9.

[52] Tiberio GA, Bonardelli S, Gheza F, Arru L, Cervi E, Giulini SM. Prospective randomized comparison of open versus laparoscopic management of splenic artery aneurysms: a 10-year study. Surg Endosc 2012. doi: 10.1007/s00464012-2413-2.

[53] Kim Y, Johna S. Laparoscopic excision of splenic artery aneurysm. JSLS 2013;17:132-134. doi: 10.4293/108680812X13517013317392.

[54] Obuchi T, Sasaki A, Nakajima J, Nitta H, Otsuka K, Wakabayashi G. Laparoscopic surgery for splenic artery aneurysm. Surg Laparosc Endosc Percutan Tech 2009;19:338-340. doi: 10.1097/SLE.0b013e3181a89206.

[55] Varnagy D, Sendzischew M, Hertz JA, Sendzischew H. Endovascular management of a ruptured splenic artery aneurysm. Vasc Endovascular Surg 2007; 41:68-72. doi: $10.1177 / 1538574406290209$.

[56] Roland J, Brody F, Venbrux A. Endovascular management of a splenic artery aneurysm. Surg Laparosc Endosc Percutan Tech 2007;17:459-461. doi: 10. 1097/SLE.0b013e31814a5772.

[57] Schmidt JH, Howard RJ, Herrera MA, Hawkins IF. Splenic arteriovenous fistula with portal hypertension, ascites, and diarrhea. South Med J 1988; 81:670-672. doi: 10.1097/00007611-198805000-00033.

[58] Siablis D, Papathanassiou ZG, Karnabatidis D, Christeas N, Katsanos K, Vagianos C. Splenic arteriovenous fistula and sudden onset of portal hypertension as complications of a ruptured splenic artery aneurysm: Successful treatment with transcatheter arterial embolization. A case study and review of the literature. World J Gastroenterol 2006;12:4264-4266. doi: 10.3748/ wjg.v12.i26.4264.

[59] Yadav R, Tiwari MK, Mathur RM, Verma AK. Unusually giant splenic artery and vein aneurysm with arteriovenous fistula with hypersplenism in a nulliparous woman. Interact Cardiovasc Thorac Surg 2009;8:384-386. doi: 10.1510/ icvts.2008.196121.

[60] Saddekni S, Anis KH, Hegazi AA, Hamed MF, Abdel Aal AK. Traumatic complex splenic arteriovenous fistula causing prehepatic portal hypertension and variceal bleeding: the importance of the diagnosis for the endovascular treatment approach. Vasc Endovascular Surg 2014;48:180-185. doi: 10.1177/ 1538574413513340

[61] Azar CR, Al-Kutoubi AO, Mourad FH. A short case of a splenic arteriovenous fistula coexisting with portal hypertension secondary to hepatitis C: Radiologic diagnosis and treatment. J Med Imaging Radiat Oncol 2010;54: 134-136. doi: 10.1111/j.1754-9485.2010.02151.x.

[62] Buchholz RR. Arteriovenous fistula of the splenic vessels; report of a case following splenectomy. Ann Surg 1959;149:590-592. doi: 10.1097/00000658195904000-00023.

[63] Piscaglia F, Valgimigli M, Serra C, Donati G, Gramantieri L, Bolondi L. Duplex Doppler findings in splenic arteriovenous fistula. J Clin Ultrasound 1998;26: 103-105. doi: 10.1002/(SICI)1097-0096(199802)26:2<103::AID-JCU10>3. $0 . \mathrm{CO} ; 2-\mathrm{N}$.

[64] Ueda T, Murata S, Yamamoto A, Tamai J, Kobayashi Y, Hiranuma C, et al. Endovascular treatment of post-laparoscopic pancreatectomy splenic arteriovenous fistula with splenic vein aneurysm. World J Gastroenterol 2015; 21:7907-7910. doi: 10.3748/wjg.v21.i25.7907.

[65] Tun TN, Punamiya S. Gastric variceal bleeding precipitated by a mycotic splenic arteriovenous fistula in a cirrhotic patient: radiological diagnosis and endovascular treatment. Singapore Med J 2014;55:e180-e183. doi: 10.11622/smedj.2014166

[66] Chen JS, Chuang SC, Wang SN, Chang WT, Kuo KK, Lee KT, et al. Natural course of splenic artery aneurysm with associated spontaneous splenorenal shunt in non-cirrhotic liver: an 18-year observational follow-up and review of literature. Kaohsiung J Med Sci 2013;29:55-58. doi: 10.1016/j.kjms.2012. 08.009 .

[67] Tarantino G, Citro V, Conca P, Riccio A, Tarantino M, Capone D, et al. What are the implications of the spontaneous spleno-renal shunts in liver cirrhosis? BMC Gastroenterol 2009;9:89. doi: 10.1186/1471-230X-9-89.

[68] von Herbay A, Frieling T, Häussinger D. Color Doppler sonographic evaluation of spontaneous portosystemic shunts and inversion of portal venous flow in 
patients with cirrhosis. J Clin Ultrasound 2000;28:332-339. doi: $10.1002 /$ 1097-0096(200009)28:7<332: :AID-JCU3>3.0.CO;2-9.

[69] Culafic D, Perisic M, Vojinovic-Culafic V, Sagic D, Kerkez M. Spontaneous splenorenal shunt in a patient with liver cirrhosis and hypertrophic caudal lobe. J Gastrointestin Liver Dis 2006;15:289-292.

[70] Cacciapaglia F, Vadacca M, Coppolino G, Buzzulini F, Rigon A, Zennaro D, et al. Spontaneous splenorenal shunt in a patient with antiphospholipid syndrome: the first case reported. Lupus 2007;16:56-58. doi: 10.1177/ 0961203306072390.

[71] Ji EK, Yoo SJ, Kim JH, Cho KS. Congenital splenorenal venous shunt detected by prenatal ultrasonography. J Ultrasound Med 1999;18:437-439. doi: 10. 7863/jum.1999.18.6.437.

[72] Bagheri M, Hajati A, Hosseini M, Ostad SP. Comparison of findings of spontaneous splenorenal shunt in color Doppler sonography with multislice CT scan (64 slices) in liver transplant candidates. Eur J Radiol 2012;81:2027-2036. doi: 10.1016/j.ejrad.2011.06.008.
[73] Lee SG, Moon DB, Ahn CS, Kim KH, Hwang S, Park KM, et al. Ligation of left renal vein for large spontaneous splenorenal shunt to prevent portal flow steal in adult living donor liver transplantation. Transpl Int 2007;20:45-50. doi: $10.1111 /$ j.1432-2277.2006.00392.x.

[74] Tallón Aguilar L, Jiménez Riera G, Suárez Artacho G, Marín Gómez LM, Serrano Díaz-Canedo J, Gómez Bravo MA. Posttransplantation portal thrombosis secondary to splenorenal shunt persistence. Transplant Proc 2010;42: 3169-3170. doi: 10.1016/j.transproceed.2010.05.075.

[75] Rogal SS, Hu A, Bandi R, Shaikh O. Novel therapy for non-cirrhotic hyperammonemia due to a spontaneous splenorenal shunt. World J Gastroenterol 2014;20:8288-8291. doi: 10.3748/wjg.v20.i25.8288.

[76] Zamora CA, Sugimoto K, Tsurusaki M, Yamaguchi M, Izaki K, Taniguchi T, et al. Portosplenic blood flow separation in a patient with portosystemic encephalopathy and a spontaneous splenorenal shunt. J Vasc Interv Radiol 2004;15:875-879. doi: 10.1097/01.RVI.0000136984.47892.4C. 